\title{
光触媒抗菌試験条件がチタン基板上の 大腸菌生存率に与える影響
}

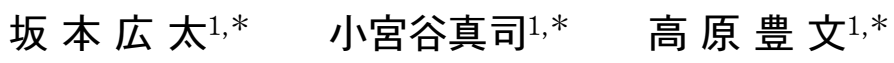 \\ 住佐 $太^{2}$ 大津直 史 ${ }^{1}$
}

${ }^{1}$ 北見工業大学機器分析センター

2北見工業大学バイオ環境化学科

J. Japan Inst. Met. Mater. Vol. 78, No. 4 (2014), pp. 159-162

(C) 2014 The Japan Institute of Metals and Materials

\section{Effect of Testing Conditions for Photocatalytic Antibacterial Performance on Escherichia Coli Survival Rate of Ti Substrate}

\author{
Kouta Sakamoto ${ }^{1, *}$, Shinji Komiya ${ }^{1, *}$, Toyofumi Takahara ${ }^{1, *}$, \\ Futoshi Sumisa ${ }^{2}$ and Naofumi Ohtsu ${ }^{1}$ \\ ${ }^{1}$ Instrumental Analysis Center, Kitami Institute of Technology, Kitami 090-8507 \\ ${ }^{2}$ Department of Biotechnology and Environmental Chemistry, Kitami Institute of Technology, Kitami 090-8507
}

To evaluate the antibacterial performance of photocatalytic coating, Japan Industrial Standard (JIS) committee has suggested the standard testing conditions for quantitative evaluation. However, these conditions had been constructed based on the experimental consideration from the coating formed on a glass substrate. In this study, to check the applicability of the JIS conditions to the coating on a titanium ( $\mathrm{Ti}$ ) substrate, the change of the survival rate of Escherichia coli $(E$. coli) on the Ti surface was evaluated. We confirmed that the decrease of microorganisms caused by dryness and UV-light were effectively suppressed by the use of these conditions. Furthermore, when testing the antibacterial performance of an anodic $\mathrm{TiO}_{2}$ layer on a Ti substrate, its performance could be evaluated clearly. In conclusion, we confirmed that the survival rate of $E$. coli on the Ti substrate could be evaluated by using the experimental conditions described in the JIS. [doi:10.2320/jinstmet.J2013056]

(Received August 12, 2013; Accepted January 10, 2014; Published April 1, 2014)

Keywords: titanium, photocatalyst, ultraviolet light, antibacterial activity, Escherichia coli, dryness

\section{1. 緒言}

チタン $(\mathrm{Ti})$ は，医療用ピンセット，手術用メスなどの医 療器具用素材として広く利用されている。これら医療器具を 医療行為に供するとき，細菌による感染症を防ぐために，事 前に滅菌処理を行う必要があり，医療現場では，一般に高圧 蒸気滅菌が用いられている。しかしこの処理は, 滅菌処理に 時間を要し, さらに処理終了後は器具の冷却が必要である. ゆえに, 迅速対応が求められる医療現場では不便である. 短 波長紫外光を器具に照射すると, 簡便かつ迅速に隇菌処理す ることができるが，この方法は，殺菌効果が不十分である 上, 大気中の酸素からオゾンが発生する恐れもある1). 近 年, オゾンを発生しない微弱な長波長紫外光下に拈いて優れ た抗菌性能を示す二酸化チタン $\left(\mathrm{TiO}_{2}\right)$ 光触媒が注目されて いる.この材料は, 波長 $360 \mathrm{~nm}$ 以上の長波長紫外光を照射 することで, 大気中の酸素から活性酸素を発生させ, その強

\footnotetext{
* 北見工業大学大学院生 (Graduate Student, Kitami Institute of Technology)
}

い酸化力によって細菌の細胞膜を破壊し, 抗菌性能を示 $す^{2-9)}$. この被膜を $\mathrm{Ti}$ 基板表面に形成させると, 滅菌工程の 簡略化および, コストの低減が期待できるため, 種々の方法 で $\mathrm{Ti}$ 基板表面に $\mathrm{TiO}_{2}$ 被膜を形成する研究が行われてい る $^{6,8-12)}$.

ところで，このような光触媒機能被膜を有する $\mathrm{Ti}$ 基板の 研究を効率的に進めていくためには, その抗菌性能を精確に 定量評価できる手法が必要となる. 日本工業規格 (JIS 規格) は, 試料表面に大腸菌などの細菌懸濁液を滴下し, 紫外光照 射下に 8 時間留置した後, その表面における細菌数を算出 することで, 抗菌性能を定量的に評価する試験方法(JIS R 1702) を提案している13). しかし, この試験に抢ける細菌数 の減少には, 光触媒作用によるものだけではなく, 細菌の乾 燥による死滅や紫外光自体の殺菌効果によるものも含まれる 可能性があり, 光触媒活性による抗菌性能を精確に評価する ためには，これらの効果による細菌数の減少を把握するとと もに，その影響を抑制できる試験条件の設定が肝要となる. そこで, JIS 規格では細菌の乾燥による死隇を防ぐ方法, お よび紫外光自体による殺菌効果を抑制できる照射条件を指示 している13). ところで, これらの指示は, ガラス基板上に 
形成した光触媒被膜を試料として決定したものである．金属 材料は一般に熱伝導性が高いため, 紫外光照射により表面温 度が上昇しやすく，ゆえに，試料表面付近の湿度低下が顕著 である. そのため, Ti 基板の場合, 乾燥や紫外光照射によ る細菌数減少効果は，JIS 規格における予測と異なる可能性 がある。

本研究では，光触媒活性を持たない $\mathrm{Ti}$ 基板を試料として， JIS 規格に準拠した方法で抗菌試験を実施し，その表面にお ける細菌数の推移を調べることで, 光触媒作用以外の効果に よる細菌数の減少を把握することを試みた。さらに， $\mathrm{Ti}$ 基 板上に形成した $\mathrm{TiO}_{2}$ 被膜を, 既存の JIS 規格で実際に評価 することが可能かどうかを検証した。

\section{2. 実 験 方 法}

$20 \mathrm{~mm} \times 10 \mathrm{~mm} \times 1 \mathrm{~mm}$ の純 Ti 板 $(99.9 \%)$ を，表面形状 による影響を排除するために，平均粒形 $40 \mathrm{~nm}$ のコロイド 状のシリカ懸濁液で化学研磨し, その後, エタノールおよび 蒸留水で，それぞれ 10 分間超音波洗浄した。さらに，試験 菌以外の細菌を除去するために, 波長 $253.7 \mathrm{~nm}$ の殺菌灯 $\left(20 \mu \mathrm{W} / \mathrm{cm}^{2}\right)$ を 24 時間照射したものを試料とした.

試験菌種は JIS 規格で指示されている大腸菌 (ATCC6922 株）を用いた。牛肉エキスを混入したペプトン培地を用い て，大腸菌を $37^{\circ} \mathrm{C} \cdot 24$ 時間の条件で液体培養した後，その 大腸菌懸濁液を，生理食塩水を用いて $2.0 \times 10^{7} \mathrm{CFU} / \mathrm{mL}$ (Colony-Forming Unit)に調製した. 大腸菌懸濁液 $50 \mu \mathrm{L}$ を 試料表面に滴下し，暗所抢よびブラックライト $(\lambda=365 \mathrm{~nm}$; $\left.250 \mu \mathrm{W} / \mathrm{cm}^{2}\right)$ 照射下に打りる 2 時間毎の大腸菌生存率の変 化を測定した。大腸菌生存率は一定時間後における試料上生 菌数を, 滴下直後の生菌数で割った值と定義した。 なた，生 菌数は，試料上に付着した大腸菌を，SCDLP ブィヨン培地 中で洗い出し，その培地を牛肉エキス混入ペプトン寒天培地 に塗布後，コロニーカウントすることで計測した．ここで， SCDLP ブイヨン培地とは, Soybean-Casein Digest Broth with Lecithin \& Polysorbate80の略であり, 大豆ペプトン (和光純薬工業製), カゼインペプトン(和光純薬工業製), 塩 化ナトリウム (和光純薬工業製), リン酸二水素カリウム (ナ カライテスク製)，グルコース(ナカライテスク製)，界面活 性剂の Lecithin (和光純薬工業製)，括よび Polysorbate80 (関東化学製)を用いて調合した ${ }^{14)}$ 。測定サンプル数は各試 料条件につき $N=2$ とし，これらの実験を 3 回繰り返すこと で, 大腸菌生存率の増減傾向に再現性があることを確認し た。 また，試料表面の乾燥を防ぐため，JIS 規格に準拠し て，オートクレーブ滅菌水を十分に含むろ紙を試料付近に留 置した (Fig. 1)。この乾燥防止処置有りの場合, 周囲の湿度 は 35\%程度に保持されるが，無しの場合は，10\%程度まで 低下することを確認した(Fig. 2)。 また，本研究の結果にお ける大腸菌生存率の有意差は, Student の $\mathrm{t}$ 検定，抢よび Tukey 法を用いた統計解析で検証した.

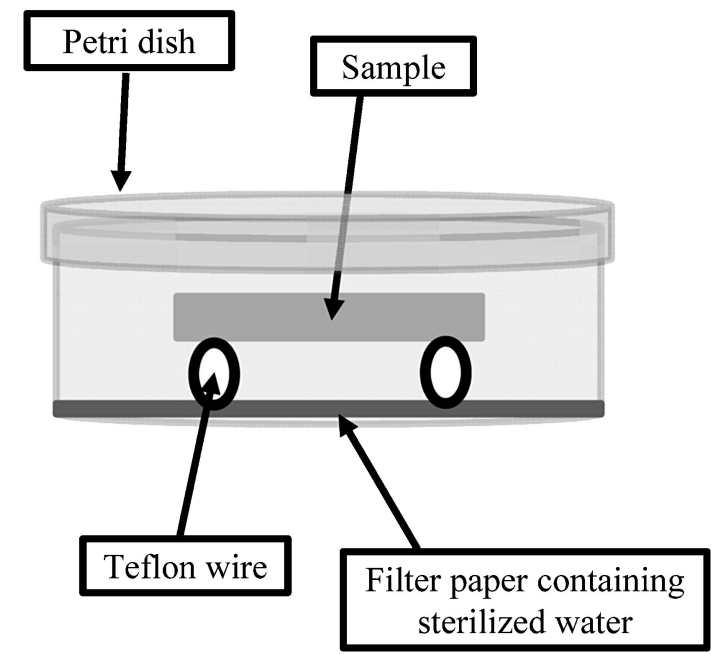

Fig. 1 Schematic illustration of the sample setting to keep humidity.

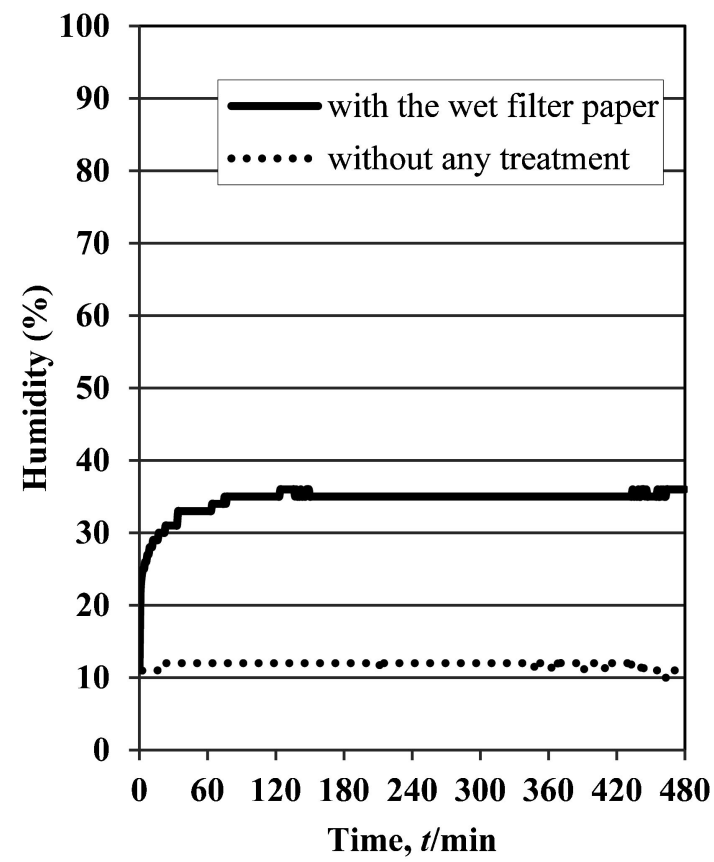

Fig. 2 Time transition of the humidity in a petri dish.

\section{3. 結 果と考察}

\section{1 乾燥が $\mathrm{Ti}$ 基板上の大腸菌生存率に与える影響}

JIS 規格では，試料表面の乾燥による細菌の死滅を減らす ための処置が指示されている．この処置が，Ti 基板におい ても有効であるかどうかを検討した．Fig. 3 は，JIS 規格に 準拠した乾燥防止処置 (Fig. 1) 有り，抢よび無しの条件下 で, 暗所に 8 時間留置したときの大腸菌生存率の経時変化 である．乾燥防止処置を行わなかった場合，4時間までは大 腸菌生存率はほぼ 100\%であるが，それ以降は，生存率は時 間経過に伴い減少し，8時間ではほぼ $30 \%$ にった。この 死滅は, 乾燥の進行によるものであると考えられる. 一方, 滅菌水を含むろ紙を留置した場合，8時間留置後でも大腸菌 生存率は減少していなかった。また，乾燥防止処置有り，お 


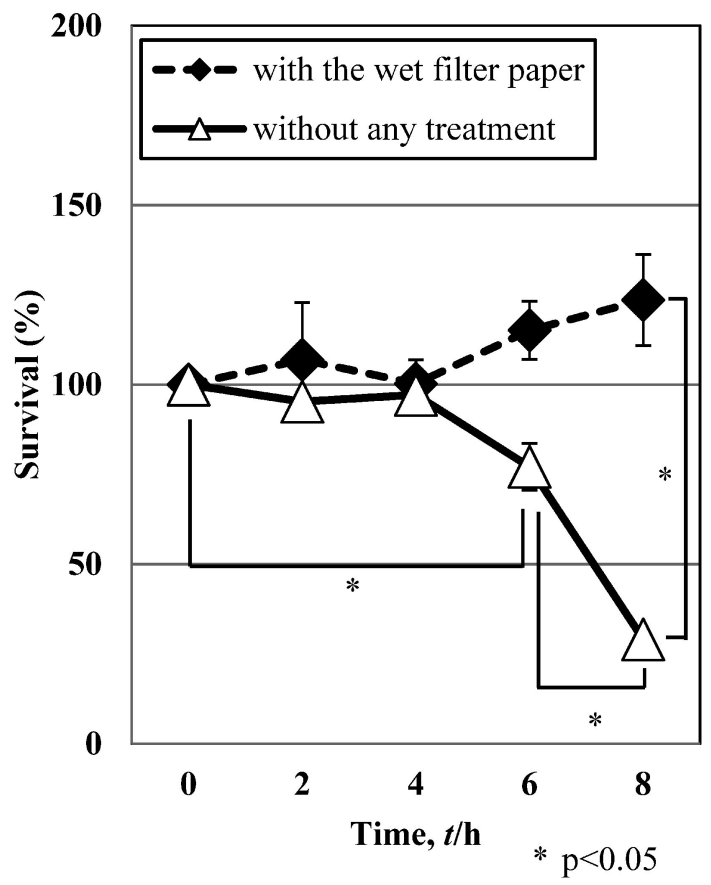

Fig. 3 Survival rate of E. coli on a Ti substrate placed in a dark with and without the wet filter paper.

よび無しの条件下における 8 時間の生存率には, 統計的有 意差があることを確認できた。これらの結果より，Ti 基板 上に抢ける抗菌性能試験に扔いて, 照射時間 4 時間以内で あれば乾燥防止処置は必要ないが，より長い時間の経時変化 を調べる場合は，湿度を保つための何らかの処置が必要であ り，その処置としてJIS で指示されているろ紙を用いる方法 は，Ti 基板の場合でも有効であることがわかった。

\section{2 紫外光照射が $\mathrm{Ti}$ 基板上の大腸菌生存率に与える影響}

波長 $365 \mathrm{~nm}$ 程度の長波長紫外光であっても，それ自体が 殺菌効果を示す. 光量が微弱である場合は殺菌効果も微弱で あるため無視できるが，光量の低下に伴い光触媒機能が十分 に発現しなくなる，そこで，JIS 規格には，これらの影響を 加味し, 試験に用いる紫外光照躬強度は $250 \mu \mathrm{W} / \mathrm{cm}^{2}$ が適 切であると記載されている，そこで本研究では，この強度の 紫外光照射が， $\mathrm{Ti}$ 基板上に存在する大腸菌の生存率に与え る影響を調査した．Fig. 4 は，細菌懸濁液を滴下した $\mathrm{Ti}$ 基 板を，紫外光 $250 \mu \mathrm{W} / \mathrm{cm}^{2}$ の照射下および暗所に 8 時間留 置したときの大腸菌生存率の経時変化である.なお，どちら の場合も滅菌水含有ろ紙による乾燥防止処置を行った。暗所 に留置した場合, 8 時間まで大腸菌生存率の減少は観察され なかった，一方，紫外光照射下に留置した場合，4 時間まで 大腸菌生存率の変化は観察されないが，6 時間で減少しはじ め, 8 時間では $70 \%$ まで減少していた。紫外光照射下およ び暗所に留置 8 時間の生存率には, 統計的有意差があるこ とを確認できた． 8 時間照射後における $\mathrm{Ti}$ 材料表面の温度 を測定すると $40^{\circ} \mathrm{C}$ 未満であったため，この死滅は，温度上 昇に起因するものではないことがわかる，すなわち， $\mathrm{Ti}$ 基 板の場合， $250 \mu \mathrm{W} / \mathrm{cm}^{2}$ の紫外光を用いることで，光触媒性 能による抗菌効果を評価可能であるが，照射時間が 6 時間

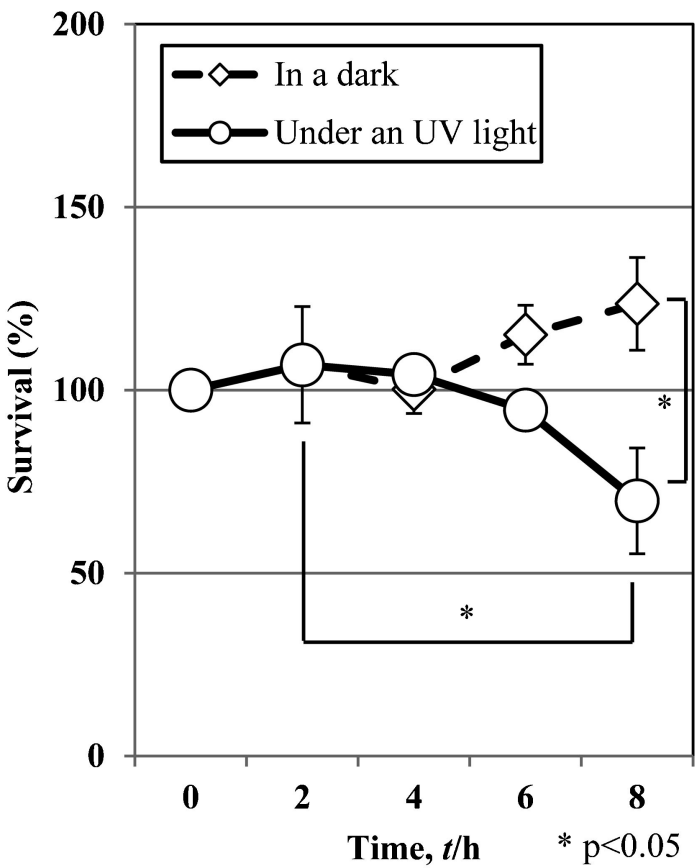

Fig. 4 Survival rate of $E$. coli on a substrate in a dark place and under an UV light.

を超過すると，紫外光自体による殺菌効果が顕著になるた め，その減少分を事前に見積もっておく必要があることがわ かった。

\section{3 陽極酸化 $\mathrm{Ti}$ 基板への光触媒抗菌試験の適用例}

JIS に規定されている乾燥防止処置 (Fig. 1) 抢よび，紫外 光照射条件を用いることで， Ti 基板上に抢ける大腸菌の乾 燥による死滅抢よび紫外光自体による殺菌効果を抑制できる と考えられる．そこでこれらの条件を利用して，光触媒 $\mathrm{TiO}_{2}$ 被膜 $\mathrm{Ti}$ 基板の抗菌性能を実際に調べた. $\mathrm{TiO}_{2}$ 被膜は 硫酸アンモニウム化成液を用いた陽極酸化処理で作製し，メ チレンブルー (MB) 脱色試験 (JIS R 1703-2) で光触媒活性を 調べた ${ }^{11,15)}$ 。結果は Fig. 5 のと抢りである。な抢，本被膜 の表面形状，結晶構造などに関する詳細なデータは過去の文 献を参照されたい11)。

Fig. 6 は光触媒 $\mathrm{TiO}_{2}$ 被膜 $\mathrm{Ti}$ 基板を暗所もしくは紫外光 照射下に 8 時間留置したときの大腸菌生存率の経時変化て ある. 光触媒 $\mathrm{TiO}_{2}$ 被膜材料を暗所に留置した場合, 大腸菌 懸濁液滴下後 2 時間で, 生存率の僅かな減少が観察される が，統計的有意差は確認できず，4 時間以降は減少しなかっ た. 一方, 紫外光 $250 \mu \mathrm{W} / \mathrm{cm}^{2}$ 照射下の場合, 光触媒 $\mathrm{TiO}_{2}$ 被膜上では大腸菌懸濁液滴下後 2 時間で生存率 $50 \%$ 以下ま で減少し，さらに，4 時間以降は，ほぼ $0 \%$ となった。また， 2 時間以降で, 紫外光照射下抢よび暗所における生存率に, 統計的有意差があることが確認できた。すなわち，強度 250 $\mu \mathrm{W} / \mathrm{cm}^{2}$ の紫外光は, 紫外光自体による殺菌効果が発現せ ず，さらに， $\mathrm{TiO}_{2}$ の光触媒活性を十分に引き出せることが 確認できた. 


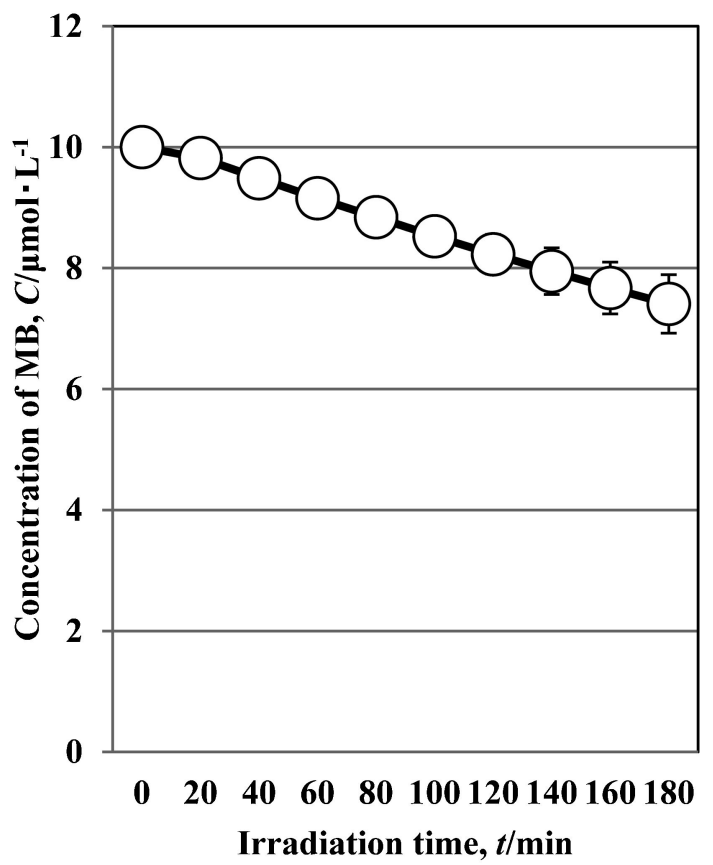

Fig. 5 Degradation of MB under an UV light, due to the photocatalytic reaction of the $\mathrm{TiO}_{2}$ coating.

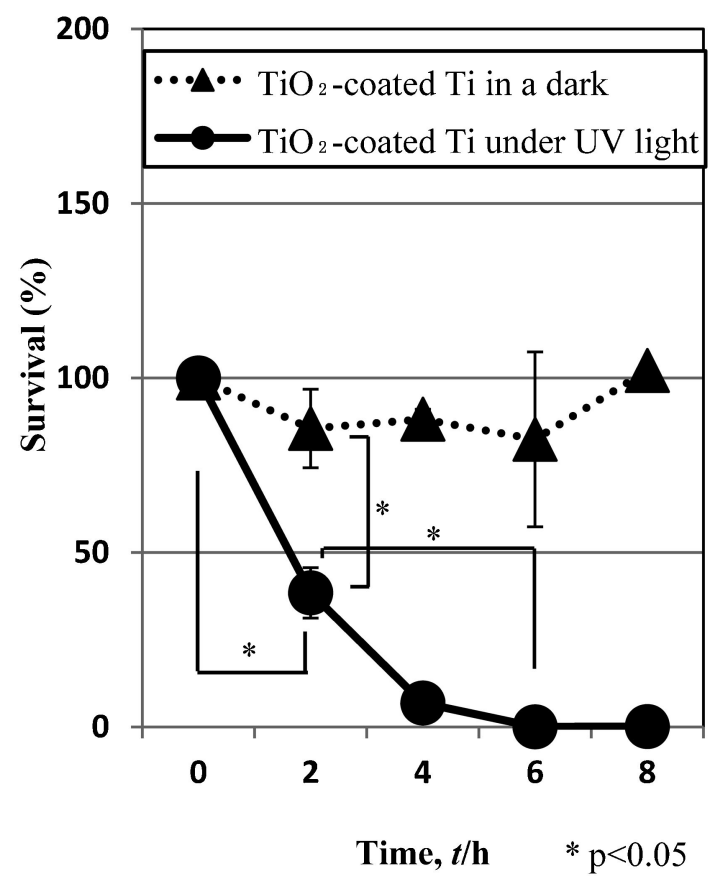

Fig. 6 Survival rate of E. coli on $\mathrm{TiO}_{2}$-coated Ti substrates in a dark and under an UV light.

\section{4. 結言}

本研究では, JIS が提案している光触媒抗菌試験の試験条 件を $\mathrm{Ti}$ 基板の場合でも，そのまま評価することが可能であ るかどうかを検討するために，光触媒機能を持たない $\mathrm{Ti}$ 基 板上に打いて, 大腸菌が受ける乾燥や紫外光照射の影響を詳 細に調査した． Ti 基板上において大腸菌は乾燥によって死 滅するが，その影響は滅菌水を含む万紙を用いた乾燥防止処 置によって抑制できることがわかった. また, 長波長紫外光 $(365 \mathrm{~nm})$ による殺菌効果は, 光量 $250 \mu \mathrm{W} / \mathrm{cm}^{2}$ 以下抢よび 照射時間 6 時間未満であればその効果はほぼ無視でき, さ らに, この紫外光強度は, 陽極酸化法を用いて作製した光触 媒 $\mathrm{TiO}_{2}$ 被膜の光触媒性能を引き出すための十分な強度であ ることがわかった．これらのことから， $\mathrm{Ti}$ 基板を用いた場 合でも，既在の JIS 規格の試験条件に則って，評価すること が可能であることが確認できた。

本研究は, JSPS 科研費基盤研究 (C) (No. 24560841)の助 成を受けて行った.

文献

1) Z. Kuluncsics, D. Perdiz, E. Brulay, B. Muel and E. Sage: Photochem. Photobiol. 49 (1999) 71-80.

2) S. Lewandowski, V. Rejsek-Riba, A. Bernes and S. Perraud: Int. J. Appl. Polym. Sci. 129 (2013) 3773-3781.

3) H. Koseki, T. Asahara, T. Shida, I. Yoda, H. Horiuchi, K. Baba and M. Osaki: Int. J. Nanomedicine 8(2013) 593-599.

4) P. Evans, T. English, D. Hammond, M. E. Pemble and D. W. Sheel: Appl. Catal. A 321 (2007) 140-146.

5) D. Alrousan, P. Dunlop, T. McMurray and J. Byrne: Water Res. 43(2009) 47-54.

6) Y. Oka, W. Kim, T. Yoshida, T. Hirashima, H. Mouri, H. Urade, Y. Itoh and T. Kubo: J. Biomed. Mater. Res. B 86(2008) $530-540$.

7) A. K. Benabbou, Z. Derriche, C. Felix, P. Lejeune and C. Guillard: Appl. Catal. B 76(2007) 257-263.

8) F. Sayilkan, M. Asilturk, N. Kiraz, E. Burunkaya, E. Arpac and H. Sayilkan: J. Hazard. Mater. 162(2009) 1309-1316.

9) J. Choi, C. J. Chung, K. Oh, Y. Choi and K. Kim: Angle Orthodontist 79(2009) No. 3.

10) N. Ohtsu, H. Kanno, S. Komiya, Y. Mizukoshi and N. Masahashi: Appl. Surf. Sci. 270(2013) 513-518.

11) N. Ohtsu, S. Komiya and K. Kodama: Thin Solid Films 534 (2013) $70-75$.

12) C. Zhao, B. Feng, Y. Li, J. Tan, X. Lu and J. Weng: Appl. Surf. Sci. $280(2013)$ 8-14.

13) JIS R 1702: $2006(\mathrm{~J})$

14) H. Shintani, E. Taniai, A. Miki, S. Kurosu and F. Hayashi: J. Hosp. Infect. 56(2004) 42-48.

15) JIS R 1703-2: 2007 (J) 